ISSN 0001-6002/2003/45/4/165-169

Acta Médica Costarricense,(@2003

Colegio de Médicos y Cirujanos

\title{
Hepatitis virales agudas en un hospital de adultos, de 1992 a 2001
}

\author{
José Acuña ${ }^{1}$, Elizabeth Umaña ${ }^{1}$, Mauricio Saldarriaga ${ }^{2}$, Jorge Mora ${ }^{3}$, Fernando Brenes ${ }^{4}$, Alfredo Martén ${ }^{1}$
}

Justificación y objetivos: Debido al cambio de la distribución etiológica de las hepatitis virales agudas, percibido en la práctica clínica diaria en el ámbito nacional y confirmado en otros países, se hizo evidente la necesidad de realizar un análisis casuístico de las infecciones virales hepáticas agudas en nuestro país. Se puso enfasis en el virus productor de hepatitis Acuya presentación clínica es más severa en adultos en comparación con los niños.

Métodos: Se registraron todos los casos de hepatitis viral aguda, ya fuese por virus Ao virus B, que se presentaron al Hospital México del 12 de enero de 1992 al 28 de diciembre de 2001. El diagnóstico se realizó por detección de anti-VHAIgM, HbsAg y anti-HBc IgM. Además, se estudiaron todos los casos de hepatitis fulminante del mismo período, basados en parámetros clínicos y de laboratorio, para establecer el diagnóstico y la etiología.

Resultados: Durante el período descrito, se lograron documentar 587 casos de hepatitis virales agudas, 235 por virus A y 352 por virus B lo que corresponde al $40 \%$ y al $60 \%$ respectivamente. Se presentaron con mayor frecuencia casos entre los 20 y 60 años. El 53,32\% de los casos de hepatitis viral aguda correspondieron a hombres y el $46,68 \%$, a mujeres.

Se recolectaron 33 casos de hepatitis fulminante. De estos casos, 45,45\% eran de etiología viral; un 33,33\%, por virus Ay un 12,12\%, por virus B. Se hallaron otras etiologías en menores porcentajes, como enfermedad de Wilson, hepatotoxicidad por anestésicos y degeneración grasa del embarazo. Un 2,56\% del total de hepatitis virales se presentaron como hepatitis fulminantes. El 4,7\% de hepatitis Acursó de forma fulminante. El manejo de los pacientes con hepatitis viral aguda se ofreció en su mayoría (62\%) por medio del Servicio de Consulta Externa.

Conclusiones: La infección por el virus de la hepatitis B fue predominante en los adultos estudiados, con distribución etiológica similar a lo reportado décadas atrás para zonas específicas del país. Aunque la distribución fue similar si se denota un número importante de hepatitis A de presentación fulminante, alcanzando un porcentaje del $4,7 \%$.

Se debe considerar en el futuro panorama de la salud nacional, la incursión de una vacuna para el virus de hepatitis A, que se inicie al nacimiento y se aplique a jóvenes y adultos en mayor riesgo.

Descriptores: hepatitis, virales, agudas, fulminantes, virus de hepatitis A

Recibido: 3 de junio de 2003

Aceptado: 23 de septiembre de 2003

\footnotetext{
Abreviaturas: CCSS, Caja Costarricense de Seguro Social; UCR, Universidad de Costa Rica; VHA, virus de hepatitis A; VHB, virus de hepatitis B.

${ }^{1}$ Unidad Académica de Hepatología, Hospital México, CCSS-UCR.

${ }^{2}$ Servicio de Urgencias, Hospital México, CCSS-UCR.

${ }^{3}$ Servicio de Infectología y Servicio de Terapia Intensiva, Hospital México, CCSS-UCR.

${ }^{4}$ Servicio de Anatomía Patológica, Hospital México, CCSS-UCR.

Correspondencia: José Alonso Acuña Feoli, correo postal: 186-2300

Curridabat, facsímil: 271-2861.
}

Las hepatitis virales son enfermedades infectocontagiosas de declaración obligatoria, que han ido cobrando mayor relevancia en la población adulta mundial y de Costa Rica'. En el ámbito global se reportan 1.4 millones de nuevos casos de hepatitis. Anualmente, aunque se piensa la verdadera incidencia es 10 veces mayor ${ }^{2-3}$.Aproximadamente, 20 millones de nuevas infecciones por virus de hepatitis B son reportadas por año en todo el mundo ${ }^{4}$. Estos hechos se asocian a un aumento en la morbilidad y mortalidad de tal grupo etario, con las implicaciones económicas directas e indirectas que acarrea para el país tal hecho. Por ello las hepatitis virales agudas representan una preocupación considerable para el sistema de salud nacional. 
En publicaciones previas ${ }^{5}$ se ha demostrado que en menores de 15 años las diferentes etiologías para hepatitis virales se distribuyen de la siguiente manera: por virus de hepatitis $\mathrm{A}$ (VHA) un $88,04 \%$, por virus de hepatitis B (VHB) un $11,22 \%$ y por etiología no determinada un $0,74 \%$. En mayores de 30 años, la distribución es así: un 59,18\% por VHB, un $19,39 \%$ por VHA y un $21,43 \%$ de etiología indeterminada.

Ante la hipótesis que la distribución etiológica de las hepatitis virales podría estar cambiando, hemos propuesto revisar la casuística de las hepatitis virales agudas en un hospital de adultos, durante en un período de 10 años (1992-2001).

Las hepatitis producidas por el VHB y el virus de hepatitis C se estudian con frecuencia en adultos ${ }^{4,6}$. El VHA se ha estudiado más frecuentemente en niños y adolescentes 7 . Por esta razón en la casuística de este trabajo, es nuestro interés poner énfasis en el VHA en adultos

La hepatitis $\mathrm{A}$ es una enfermedad necroinflamatoria aguda del hígado, por la infección con el virus de la hepatitis A $(\mathrm{VHA})^{6}$. Este virus es un picornavirus del género de los hepatovirus $^{3,8}$. Debe su nombre a su pequeño tamaño de 27-28 nm (de allí el prefijo pico) y a que su genoma consta de ARN (por eso las letras rna). La principal forma de transmisión es por vía fecal-oral, por lo que está particularmente asociado a los bajos niveles de higiene y pobres medidas sanitarias ${ }^{3.8}$, aunque también se ha descrito la vía parenteral como mecanismo de infección; esta forma cobra mayor importancia en el adulto ${ }^{6}$, en especial en homosexuales ${ }^{9}$.

En los países en vías de desarrollo con alta endemicidad por hepatitis A, se ha observado que las tasas de seroprevalencia se aproximan al 100\% en la infancia tardía y en el adulto jo$v^{v e n}{ }^{3}$. En estas áreas hiperendémicas, la mayoría de las infecciones ocurren en niños menores de 5 años. En contraste, las tasas de seroprevalencia han caído en los países industrializados, y solo el 35\% de los adultos y menos del 10\% de los niños menores de 5 años presentan anticuerpos contra el VHA en los Estados Unidos 7 . Esta disminución de la inmunidad natural por exposición al VHAen edades tempranas conduce a un incremento en el número de adultos susceptibles a la infección, por lo que en países desarrollados existen mayores probabilidades de que se presenten brotes epidémicos periódicos ${ }^{10,11-8}$. En Costa Rica, la hepatitis Apasó de tener una prevalencia alta a una de intermedia a baja, con seroprevalencias para VHAdel $6.8 \%$, el $13.2 \%$ y el $71.7 \%$ en preescolares, escolares y adultos, respectivamente ${ }^{12}$.

El curso clínico típico de la hepatitis Atiene 4 etapas: 1) período de incubación, 2) fase prodrómica, 3) fase ictérica y 4) recuperación. El período de incubación varía entre 15 y 50 días, con una duración promedio de casi un mes ${ }^{3,6}$. Es en esta fase cuando la excreción viral en heces alcanza su máximo nivel en el paciente que esencialmente es asintomático ${ }^{3}$. En la fase prodrómica aparecen síntomas inespecíficos como fiebre, náuseas, vómitos, pérdida de peso, astenia y adinamia, que duran cerca de una semana. Durante este lapso inicia el daño hepatocelular. Hacia el final de la semana los pacientes presentan coluria, acolia e ictericia. La fase ictérica puede durar desde unos pocos días hasta varias semanas. Se acompaña de anorexia, fiebre y prurito, mientras los síntomas prodrómicos tienden a abatirse. La recuperación de la hepatitis A es gradual. La función hepática regresa a lo normal casi después de 3 meses, pero las sensaciones de debilidad y letargia pueden persistir hasta durante 1 año. No se conocen casos de portador del VHAo hepatitis crónica por este virus.

La presentación clínica de la hepatitis A varía según la $\operatorname{edad}^{6,8,12}$. En niños menores de 3 años, por lo general la infección cursa asintomática. Los niños mayores presentan un cuadro más evidente, asociando con frecuencia náuseas, vómitos, diarrea, dolor abdominal y malestar general durante la fase prodrómica. El adulto tiende a presentar la sintomatología típica de una virosis durante el pródromo, con fiebre, cefalea, mialgias, artralgias e hiporexia. La morbilidad y mortalidad también cambian según la edad, presentando mayores complicaciones en el adulto mayor y menores en niños. Se han reportado tasas de mortalidad del 0,3\% para pacientes de 15 a 19 años y del 2,1\% para mayores de 40 años.

En la práctica clínica la forma más frecuente de detección de infección por VHA consiste en medir las aminotransferasas y anti-VHA IgM en suero ${ }^{3,6}$. Las transaminasas tienden a elevarse desde el período prodrómico hasta alcanzar un pico en la fase ictérica ${ }^{6}$. Los anti-VHA IgM se producen en respuesta primaria a la infección y se puede detectar desde que los síntomas prodrómicos se desarrollan hasta varios meses después $^{3}$. La detección de anti-VHA IgG es la forma de confirmar la inmunidad natural al VHA en una persona ${ }^{3,6,12}$ (Figura 1).

\section{Curvas serológicas en infección por VHA y excreción del virus}

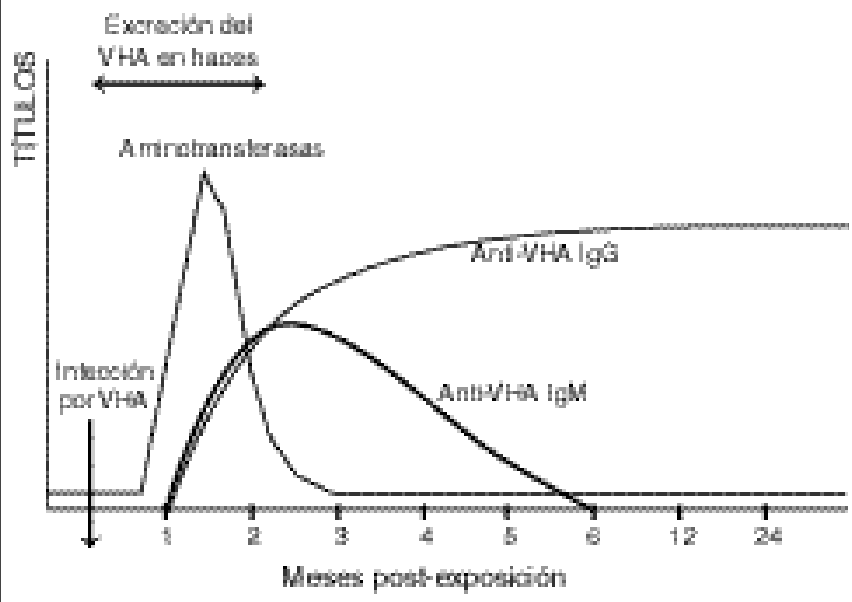

Figura 1.Gráfica que muestra el aumento de las transaminasas y títulos de anticuerpos séricos posterior a la infección con el VHA. También se señala la excreción del virus en heces. Adaptación gráfica emitida por el CDC en 2002. Elaborado por Eizabeth Umaña y José Acuña. 
La hepatitis A normalmente es una enfermedad autolimitada que confiere inmunidad de por vida ${ }^{3,6,12,13}$. Sin embargo, la infección puede tener un curso distinto, presentando complicaciones como la hepatitis A de evolución prolongada, hepatitis Ade repetición, hepatitis A fulminante, ictericia colestásica y desencadenamiento de una hepatitis autoinmune activa crónica tipo ${ }^{13,6}$.

La hepatitis A fulminante es la complicación más temida, aunque sea un acontecimiento raro (aproximadamente un $2 \%{ }^{13}$, con reportes que varían de 3,9-20\% ${ }^{14,15,16}$ ). La necrosis hepática masiva se presenta con mayor frecuencia en adultos ancianos y personas con enfermedad hepática subyacente6. La combinación de una veloz disminución del tamaño del hígado, de un aumento muy rápido de la concentración de bilirrubina y de un alargamiento marcado del TP, junto con signos clínicos de confusión, desorientación, somnolencia, ascitis y edemas, indican que el paciente tiene una insuficiencia hepática con encefalopatía ${ }^{3,6}$. Es frecuente el edema cerebral $^{13,6}$. Los acontecimientos terminales habituales son la compresión del tronco cerebral, la hemorragia gastrointestinal, la sepsis, la insuficiencia respiratoria, el colapso cardiovascular y la insuficiencia renal. La mortalidad es muy elevada ( $>80 \%$ ), pero los enfermos que sobreviven pueden experimentar recuperación bioquímica e histológica completa. El trasplante hepático puede salvar la vida de pacientes con hepatitis fulminante ${ }^{6}$.

\section{Materiales y métodos}

En este trabajo se registraron todos los pacientes con diagnóstico de hepatitis viral aguda, por VHA o VHB, que se presentaron al Hospital México, del 12 de enero de 1992 al 28 de diciembre de 2001. El diagnóstico se realizó por medio de la confirmación serológica de infección aguda. Se utilizaron parámetros como aminotransferasas significativamente elevadas (en general en el orden de las centenas). En el caso de hepatitis A, el diagnóstico se efectuó tras la detección de anti-VHB IgM. Para determinar la infección por VHB se utilizaron marcadores serológicos de infección aguda, como el HbsAg y el anti-HBc IgM. Se estudiaron los casos de hepatitis A y su severidad en esta misma población.

La información se recabó de los expedientes del Servicio de Urgencias Médicas, de la Unidad de Terapia Intensiva, de la Consulta Externa de Gastroenterología, de la Oficina de Bioestadística y del Servicio Anatomía Patológica del Hospital México de la Caja Costarricense de Seguro Social, entre el 12 de enero de 1992 y el 28 de diciembre de 2001.

Además, se registraron todos aquellos casos de hepatitis fulminante que se presentados en el mismo período, y se estableció la etiología para cada uno de ellos. El diagnóstico de hepatitis fulminante fue basado en la conjunción de los siguientes datos: tiempo de protrombina persistentemente inferior al 50\%, y datos de encefalopatía hepática y aminotransferasas iniciales al período de observación sobre 2000 UI/l, que descendieran de manera progresiva y paralela a la reducción del tamaño hepático.

\section{Resultados}

Durante el período descrito, se logró documentar 587 casos de hepatitis virales agudas, de los cuales 235 (40\%) correspondieron a hepatitis por VHAy $352(60 \%)$ enfermedad aguda por VHB.

En lo concerniente a la distribución de los casos recolectados por grupo etario, se presentaron con mayor frecuencia casos entre los 20 y 60 años. También se registraron menos casos en los extremos de los grupos etarios, tanto para los niños como para los pacientes de edades avanzadas. En total 53,32\% de los casos de hepatitis viral aguda correspondieron a hombres y $46,68 \%$ a mujeres (Figura 2 ).

Se estudiaron los casos de hepatitis fulminante en el período ya señalado, documentando 33 casos que cumplían con los criterios diagnósticos de dicha entidad clínica. De estos casos, $45,45 \%$ eran de etiología viral; $33,33 \%$ por VHA y $12,12 \%$ por VHB. Se halló $12,12 \%$ de enfermedad de Wilson de presentación fulminante. 9,09\% correspondió a hepatotoxicidad por anestésicos. También hubo 6,06\% de los casos, donde se documentó degeneración grasa del embarazo. Se pudo detallar la etiología tóxica por otras sustancias en $6,06 \%$, mientras que en el $21,21 \%$ de los casos no se logró precisar la etiología específica.

Las 15 hepatitis virales fulminantes, tanto A como B, representan el 2,56\% del total de 587 hepatitis virales. Los 11 casos de hepatitis fulminantes producidas por el VHA, representan el $4,7 \%$ del total de 235 hepatitis por virus A. Es de importancia recalcar que las 11 hepatitis fulminantes producidas por el VHA, representan el $1.9 \%$ del total de 587 hepatitis virales agudas.

El manejo de los pacientes con hepatitis viral aguda se dio en su mayoría a través de Consulta Externa en 366 de los casos, en el Servicio de Emergencias en 124 casos, en los Salones de Medicina en 82 casos y requirieron manejo en la Unidad de Terapia Intensiva 15 casos. La estancia promedio en el Servicio de Medicina fue de 14,92 días mientras en la Unidad de Terapia Intensiva fue de 7,45 días (Figura 3).

\begin{tabular}{|cc|}
\hline \multicolumn{2}{|c|}{ Cuadro 1. } \\
$\begin{array}{c}\text { Cuadro que muestra el número absoluto de casos } \\
\text { de hepatitis fulminantes según etiología. }\end{array}$ \\
\hline Casos de hepatitis fulminante según etiología \\
\hline Etiología & Número de casos \\
\hline Virus de hepatitis A & 11 \\
Virus de hepatitis B & 4 \\
Wilson & 4 \\
Anestésicos & 3 \\
Degeneración grasa del embarazo & 2 \\
Tóxicos & 2 \\
Sin etiología & 7 \\
\hline
\end{tabular}




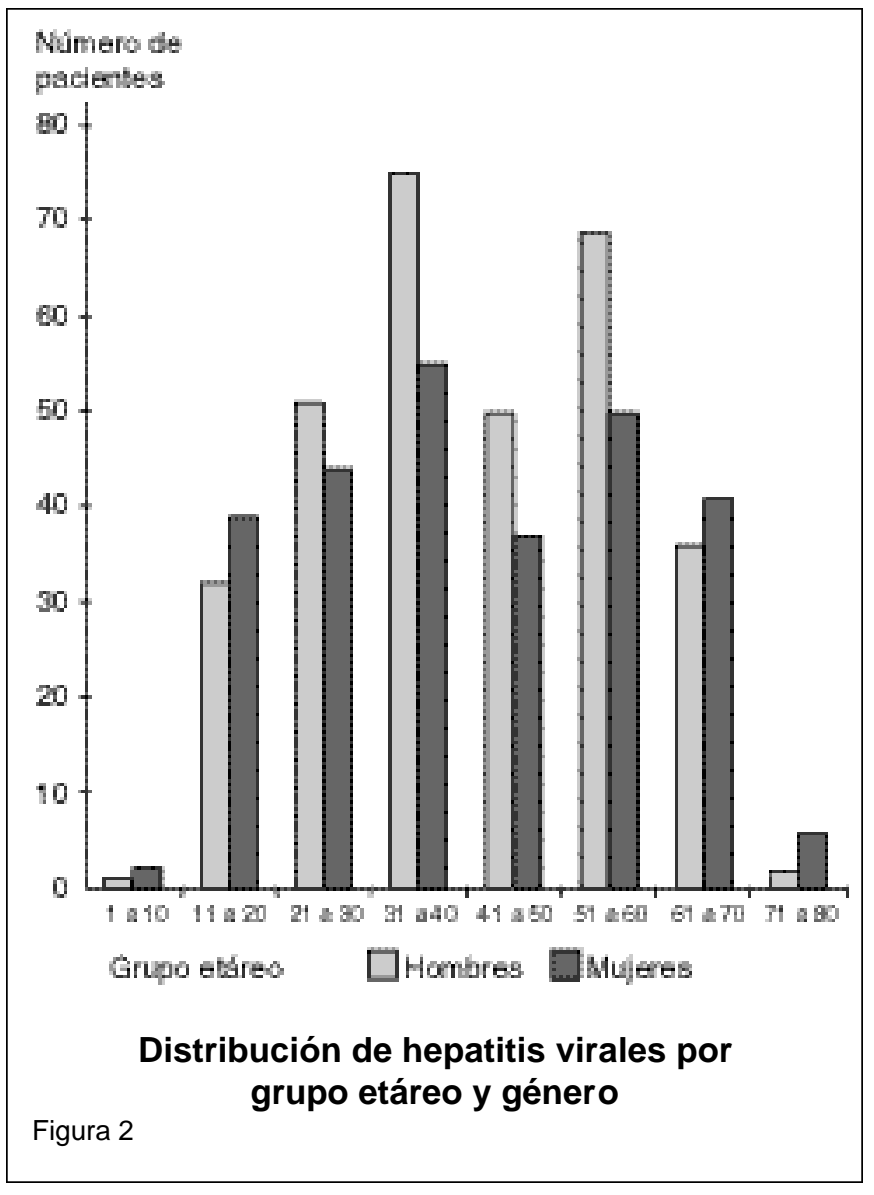

\section{Discusión}

En los adultos estudiados con hepatitis viral aguda predominó la infección por el virus de la hepatitis B. Esto es concordante con lo que con anterioridad se había documentado entre 1972 y 1985 en nuestro país para la zona de San Ramón y Palmares en pacientes mayores de 15 años y mayores de 30 años ${ }^{5}$.

En cuanto a la distribución por grupos de edad, se aprecia un predominio marcado de infecciones agudas virales hepáticas en los grupos etarios de edad intermedia. Si se compara con lo obtenido en trabajos de epidemiología de las décadas previas $^{14}$, se notará que el predominio difiere de manera importante pues en aquel momento se registró una incidencia mayor en el grupo etario de los 5 a 9 años. Esto lo podemos explicar en parte, por el hecho de que los datos recolectados pertenecen a un hospital de adultos por lo que el número de casos reportados en los grupos etarios de 1 a 10 años y de 11 a 20 años será estimablemente menor al real para la población pediátrica costarricense. Además este bajo registro de casos en niños podría deberse, aunque en menor parte tal vez, a una verdadera disminución de la infección viral hepática aguda; como ya se ha demostrado, basándose en la disminución de la seroprevalencia para hepatitis A en preescolares y escolares $^{12}$.

En lo que respecta a la infección por virus de hepatitis A en edades tempranas, parece ser evidente el cambio positivo

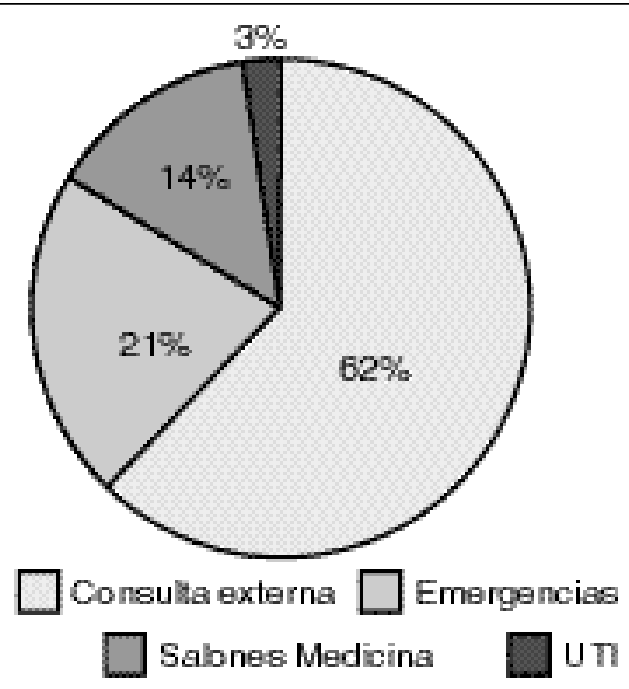

\section{Lugar de manejo de los casos de hepatitis virales agudas}

Figura 3.Diferentes servicios médicos donde se brindó manejo y seguimiento a los casos de hepatitis virales agudas.

generado a raíz de las mejoras en la salubridad pública del país en las últimas décadas ${ }^{1}$, pero esta ganancia tiene su contraparte negativa: los jóvenes y adultos de los estratos medio y alto de Costa Rica se encuentran en mayor riesgo de infección sintomática de mayor severidad al existir pocas probabilidades de exposición al VHApara crear inmunidad natural a edades tempranas. Esto se demuestra con el porcentaje elevado de hepatitis A que desarrollaron hepatitis fulminante $(4,7 \%)$. En otras latitudes se ha demostrado que el uso de vacunas eficaces contra el VHA aislado o en combinación con el VHB conlleva grandes beneficios a largo plazo para pacientes en mayor riesgo de infección ${ }^{17,18}$. Se recomienda la vacunación al nacimiento en zonas de baja endemicidad, como nuestro país, y en adultos de mayor riesgo ${ }^{17}$. Por ello consideramos que el curso de esta enfermedad viral podría verse dramáticamente alterado con la incursión de vacunas que brinden una inmunidad adquirida a aquellos en mayor riesgo de contraer la infección en etapas tardías de su vida (jóvenes y adultos de clases sociales media y alta) o que por su pobre condición hepática subyacente se encuentren en mayor vulnerabilidad de presentar hepatitis severas.

Se debe mencionar que dentro de las hepatitis fulminantes en este período revisado de 10 años, la causalidad absoluta más común fue la infección con VHA.

El manejo de las hepatitis virales agudas en la mayoría de las ocasiones se podrá hacer de manera extrahospitalaria y solo unos cuantos casos requerirán intervenciones médicas en la unidad de terapia intensiva. Parece claro que la estancia hospitalaria cuando llega a ser necesaria es importante (ronda un aproximado de 15 días), lo que representa gran cantidad de costos para el sistema de salud nacional. Se puede concluir que la estancia de los pacientes en la UTI fue mucho menor por el agravante de un proceso fulminante subyacente que 
impide la evolución hacia la recuperación que se espera en los pacientes con hepatitis virales agudas.

\section{Abstract}

Objectives and justification: Due to the change that has been sensed in Costa Rica's daily clinical practice and confirmed in other countries regarding etiological distribution of acute viral hepatitis, it became clear the need of studying acute viral hepatitis infections, with more interest in the hepatitis A virus because its clinical presentation in adults is more severe tan in children.

Methods: All cases of acute AB viral hepatitis were registered, from January 12, 1992 to December 28, 2001 at the Hospital Mexico. The diagnosis was made by detection of $\operatorname{IgM}$ anti-HAV, HbsAg and IgM anti-HBc. All cases of fulminant hepatitis from the same period were studied also. The diagnosis and etiology of these cases were based on clinical and laboratory parameters.

Results: During the study on period, 587 cases of acute viral hepatitis were diagnosted, 235 by Avirus and 352 by B virus, this corresponds to a $40 \%$ and $60 \%$ respectively. Most of the cases were found between the ages of 20 and 60 years. Fifty three percent of the cases occurred in men and 46,68\% in women.

Thirty three fulminant hepatitis cases were registered. Forty five percent were caused by viral infection; 33,33\% from virus $A$ and $12,12 \%$ from virus $B$. Other pathologies like Wilson disease, hepatotoxicity produced by the use of anesthetics and pregnancy fatty degeneration were found in smaller percentages. Two point fifty six percent of acute viral hepatitis had a fulminant clinical presentation. Four point seven percent of hepatitis Acases had a fulminant course.

The management of the patients with acute viral hepatitis was mainly conducted (62\%) by the Out-patient Gastroenterology Service.

Conclusions: The predominant hepatitis infection in adults was caused by $\mathrm{B}$ virus. The etiological distribution was very similar to previous reports made decades ago for specific areas of the country, but the presentation of fulminant hepatitis A has increased (4,7\%) considerably.

The inclusion of vaccination against hepatitis Avirus must be considered in the future of the national health system. This vaccine should be given at birth and applied to young patients and adults with high risk of acquiring severe infection.

\section{Referencias}

1. Esquivel J, Fernández L, Hevia F, Martén A, Mora J y Salom I. Diagnóstico y prevención de las hepatitis virales. $\left(1^{\mathrm{a}}\right.$ ed). EDNASSS-CCSS. San José, Costa Rica. 1990; 1-22.

2. Hadler SC. Global impact of hepatitis Avirus infection; changing patterns. En: Hollinger FB, Lemon SM, Margolis HS, eds. Viral hepatitis and liver diseases. Williams \& Wilkins, Baltimore MD; 1991: 14-20.

3. Koff RS. Hepatitis A. Lancet 1998; 351: 1643-8.

4. Steffen R, DuPont HL. Hepatitis B. En: Manual of travel medicine and health. Hamilton, London \& St. Louis. BC Decker Inc., 1999; 176-83.

5. Visoná KA, Eduarte CE, Zamora E, Salazar LM. Estudio epidemiológico de las hepatitis virales en San Ramón y Palmares de 1972-1985. Acta Med Costarric 1989; 33: 69-77.

6. Fauci et al. Harrison Principios de Medicina Interna. (14a ed). Vol. II: Cap. 295. España: Mc Graw-Hill Interamericana; 1998: 1904 -22.

7. Romero R, Lavine JE. Viral hepatitis in children. Semin Liver Disease 1994; 14: 289-302.

8. Cuthbert JA. Hepatitis A: old and new. Clin Microbiol Rev 2001; 14 : 38-58.

9. Henning KJ, Bell E, Braun J, Barker ND. Acommunity-wide outbreak of hepatitis A: risk factors for infection among homosexual and bisexual men. Am J Med 1995; 99: 132-6.

10. Lucioni C, Cipriani V, Mazzi S, Panunzio M. Cost of an outbreak hepatitis Ain Puglia, Italy. PharmacoEconomics 1998; 13: 257-66.

11. Hutin YJ, Pool V, Cramer EH, et al. Amultistate foodborne outbreak of hepatitis A. N Engl J Med 1999; 340: 595-602.

12. Taylor ML, García Z, Holst I, et al. Seroprevalencia de los virus de las hepatitis A y B en grupos etarios de Costa Rica. Acta Med Costarric 2001; 43: 153-8.

13. Hollinger FB, Ticehurst JR. Hepatitis A virus. En: Fields BN, Knipe DM, Peter MH, et al., eds. Virology. ( $3^{\mathrm{a}}$ ed). Vol. 1: Part II. Specifc Virus Families. Picornaviridae. Philadelphia. New York. Lippincott-Raven Publishers; 1996: 735-782.

14. Takahashi J, Shimizu M. Etiology and prognosis of fulminant viral hepatitis in Japan: a multicentre study.The Study Group of Fulminant Hepatitis. Gastroenterol Hepatol 1991; 6: 159-64.

15. O'Grady J. Management of acute and fulminant hepatitis A. Vaccine 1992: 10 (supl. 1): S21-S23.

16. Acharya SK, Dasarathy S, Kumer TL, et al. Fulminant hepatitis in a tropical population: clinical course, cause, and early predictors of outcome. Hepatology 1996; 23: 1448-55.

17. US Department of Health and Human Services. Prevention of hepatitis A through active or passive immunizations: recommendations of the Advisory Committee on Immunisation Practices. MMWR. 1999; 48 (RR-12): 1-37.

18. Thoelen S, Van Damme P, Leenvaar-Kuypers A, et al. The first combined vaccine against hepatitis Aand B: an overview.Vaccine 1999; 17: 1657-62. 